EstAg 33 (1998) 455-486

\title{
PABLO ¿UN CIUDADANO ROMANO?
}

Los derechos humanos, entendidos como los derechos fundamentales que el ser humano posee por el hecho de ser persona, por su propia naturaleza y dignidad, y la conciencia clara y universal de tales derechos son propios de nuestros tiempos. En nuestra sociedad moderna occidental a nadie extraña el contenido de algunos artículos de la "Declaración universal de los derechos humanos" de 1948, como por ejemplo: "Toda persona que se encuentra en situación regular sobre el territorio de un Estado tiene derecho a circular libremente en él y a escoger libremente su residencia... Nadie puede ser expulsado, en virtud de una medida individual o colectiva, del territorio del Estado del cual sea ciudadano" (Art. 13). "Toda persona tiene derecho a una nacionalidad. A nadie se privará arbitrariamente de su nacionalidad ni del derecho a cambiar de nacionalidad" (Art. 15). No obstante, en la antigüedad clásica la situación era muy distinta.

En una sociedad clasista y jurídica, como era la romana, el estatuto jurídico de cada individuo jugaba un papel muy importante, dado que sancionaba las diferencias entre los miembros de la sociedad. Los romanos eran la clase privilegiada y gozaban de prerrogativas políticas, jurídicas y sociales. El Estado romano, como los tipos análogos de Ciudad-Estado que conoció el mundo antiguo clásico, sólo brindaba protección en su ordenamiento jurídico a los miembros de la civitas romana. Únicamente los que gozaban de la ciudadanía romana eran capaces de derechos; sólo ellos tenían personalidad jurídica. En relación con el status civitatis, se dividían los hombres libres en dos grupos extremos: de un lado, los ciudadanos romanos (cives); de otro, los extranjeros (peregrini). Entre ambos grupos se encontraba otro intermedio, los latini.

En este artículo nos centraremos en un personaje muy concreto de la

1. El presente artículo forma parte de mi tesis doctoral "Die Religionspolitik des Kaisers Claudius und die paulinische Mission", presentada en la universidad de Würzburg en 1997, la cual será publicada en la colección BHS, Freiburg 1999 por Herder Verlag. El texto aquí expuesto ha sido reelaborado. 
antigüedad, en el apóstol $\mathrm{Pablo}^{2}$, con el fin de analizar si éste poseía un derecho romano, como era el de la ciudadanía romana, la cual estaba reservada a una minoría privilegiada dentro del imperio. Si el apóstol tenía dicha ciudadanía, es de suponer que la política religiosa de los Emperadores Claudio y Nerón influiría de forma distinta en su misión evangelizadora que si no la poseía: Pablo, como romano, no habría tenido ninguna dificultad con los decretos imperiales que fueron promulgados contra los judíos (mencionados en Hch 17,$6 ; 18,2$ ). Como romano se habría podido mover libremente por el imperio, lo cual habría sido un aspecto muy positivo y ventajoso para la expansión de su modelo cristiano. Por eso, considero importante tener en cuenta su situación jurídica, lo que nos ayudará a entender mejor los problemas con los que el apóstol tuvo que enfrentarse para desarrollar su actividad misionera.

Según la presentación lucana de Hechos, Pablo da a conocer por primera vez su status jurídico y social en el contexto del episodio de Filipos (Hch 16,37), cuando los pretores quieren dejar en libertad a Silas y a Pablo, pero éste les contesta: "Después de habernos azotado públicamente sin habernos

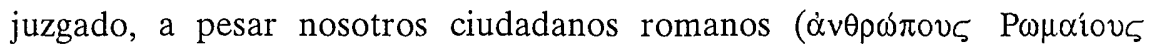

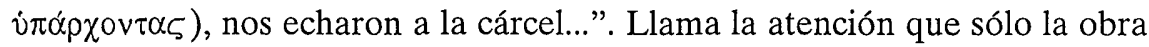
lucana de Hechos informe sobre la posesión del privilegio de la ciudadanía romana del apóstol (directamente: Hch 16,37s; 22,25ss; 23,27; indirectamente: Hch 21,39; 25,10s; 28,19), mientras que Pablo, en sus cartas, no transmite ni el más mínimo indicio de que la poseyera. Este silencio del apóstol ha sido explicado normalmente mediante los siguientes argumentos: la mención de la posesión de la nacionalidad no venía a cuento en las cartas, o que Pablo era tan humilde que no quería mencionar este privilegio. Nos podríamos preguntar si la mención de la ciudadanía romana por parte del apóstol no habría sido aconsejable y necesaria en algunos textos paulinos como en $\mathrm{Rm} 13$ o en 2 Cor 11. Y más que un apóstol humilde ¿no encontramos en sus cartas a un personaje que defiende a capa y espada su evangelio con todos los medios que tiene a su disposición? La mención de la ciudadanía romana del apóstol en Hechos está siempre en relación con los privilegios que el civis romanus gozaba en el proceso jurídico romano. Algunos autores 3 han puesto última-

2. Uno de los primeros estudios al respecto fue realizado por T: Mommsen, Die Rechtsverhältnisse des Apostels Paulus, in: ZNW 2 (1901) 81-96.

3. W. Schmithals, Apg 209s; W. Stegemann, "Anfragen" 480-490; idem, "Bürger" 200-229. $K$. Wengst, Pax 94s, argumenta de forma similar y afirma que Pablo posiblemente no dio ninguna importancia a su nacionalidad; cfr. J.C. Lentz, Portrait 43-56. Otros autores que apoyan esa teoría se pueden ver en $R$. Riesner, Frühzeit 129, nota. 1. 
mente en tela de juicio la posesión de la ciudadanía romana del apóstol por motivos histórico y sociales. La mayoría de los exégetas ${ }^{4}$, sin embargo, defienden a ultranza la tradición lucana, según la cual Pablo poseyó una doble ciudadanía: la de la ciudad de Tarso y la del imperio romano. El objetivo de este artículo será revisar dicha tesis y proponer alguna explicación de cómo y por qué Lucas presenta al apóstol como ciudadano romano.

\section{1.- Pablo, ciudadano de Tarso}

Lucas nos ofrece en Hechos el retrato de Pablo como el de un judío: Saulo, un hebreo de entre hebreos, de la tribu de Benjamíns, según la ley un fariseo, nacido en Tarso de Cilicia (Hch 22,3). Fue circuncidado según prescribía la ley judía, porque él era judío de nacimiento y no prosélito. En Hch 21,39 Lucas hace que Pablo se autopresente como un judío "de Tarso6, ciudadano de una ciudad bastante conocida de Cilicia", es decir, de una ciudad importante de Asia Menor. Su dominio de la lengua griega nos indica sin lugar a dudas su procedencia originaria de la diáspora. Siendo joven, su familia lo envió a Jerusalén para que completara su educación7. Allí fue instruido a los pies de Gamaliel el viejo (Hch 22,3), porque él, así como su familia, per-

4. Cfr. los últimos trabajos aparecidos que tratan este tema: G. Lüdemann, Christentum 249s; M. Hengel, "Paulus" 188-193; H.W. Tajra, Trial 24-29; J. Mélèze-Modrezejewski, "Tourments" 324-336; S.R. Llewelyn, "Citizenship" 152-155; R. Riesner, Frühzeit 129-139; P. van Minnen, "Paul" 43-52; K. Haacker, "Werdegang" 831-847; E. Lohse, Paulus 262s; J. Gnilka, Paulus 21-27; B. Rapske, Book 90-108; J. Murphy-O'Connor, Paul 39s.

5. Rm 11,1; 2 Cor 11,22; Flp 3,5. El apóstol tiene el nombre del primer rey de Israel, que igualmente descendía de la tribu de Benjamín. Para un retrato de Pablo como judío cfr. $B$. Rapske, Book 90-108.

6. Cuando Cilicia se convirtió en provincia romana en el año 66 a. C., Tarso fue su capital. Augusto hizo todo cuanto estaba en su mano para recompensar a esa ciudad por los sufrimientos padecidos por haber permanecido fiel a su partido (Dion Casio, XLVII 26,2); él les

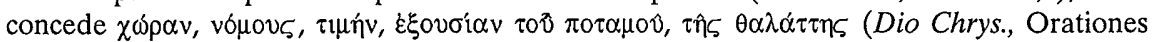
XXXIV 7,8). Plinio, nat. 5,92, la considera como una ciudad libre, con lo cual da a entender sobre todo que estaba dispensada de pagar impuestos. Gracias a Atenodoro de Tarso, el maestro de Augusto, la ciudad experimentó un gran desarrollo y prosperidad. La constitución de la ciudad tenía un carácter timocrático, es decir que el derecho de ciudadanía estaba ligado a un censo de 500 dracmas. Filostrato, Vit Apol VI 34, parece referirse a la posesión de la ciudadanía de Tarso por parte de algunos judíos en tiempos de Tito. Sobre la presencia de judíos en Tarso y sobre la posesión de ciudadanías de ciudades griegas cfr. J.C. Lentz, Portrait 32-43. En cuanto a la constitución de Tarso véase E. Meyer, Ursprung, vol. 3,311; T.B. Mitford, Roman Rough Cilicia, in: ANRW II 7.2 (1980) 1230-1261; B. Rapske, Book 72-75.

7. Tarso era el lugar de residencia del apóstol, cfr. Hch 9,30; 11,25. W.C. van Unnik, "Tarsus" 259-320, es contrario a esta tesis. De la interpretación de Hch 22,3 y 26,4-5 concluye 
tenecía al grupo de los fariseos (Hch 23,6). Lucas menciona en Hch 6,9 la existencia de una sinagoga de los Libertos en Jerusalén a la que pertenecían algunos de Cilicia. Varios exégetas presuponen que Pablo era un miembro activo de dicha sinagoga ${ }^{8}$. No sabemos nada más de su familia, exceptuando que tenía un sobrino (el hijo de su hermana), que vivía en Jerusalén (Hch 23,16-22). Muchos de estos datos biográficos no vienen confirmados directa o indirectamente en las cartas paulinas.

Este breve retrato no está exento de problemas. Su calificación religiosa ("fariseo, hijo de fariseos") en relación con su lugar de nacimiento ("Tarso") y la posesión de la ciudadanía de dicha ciudad plantean dos dificultades. La primera cuestión que se discute es su lugar de procedencia geográfica, dado que no sabemos que existieran centros farisaicos fuera de la madre patria judía 9 . El segundo problema surge a la hora de conciliar la ciudadanía de Tarso y las exigencias ciudadanas, que ésta conllevaba, con la religiosidad de los fariseos.

La primera dificultad se intenta solucionar normalmente recurriendo a dos textos de Jerónimo ${ }^{10}$, según el cual la familia de Pablo provendría de Galilea, y concretamente de Gischala. Cuando esta ciudad fue tomada por los romanos, sus padres (y tal vez Pablo) emigraron a Tarso de Cilicia. Las dos noticias de Jerónimo, sin embargo, no concuerdan entre si, y no es fácil determinar a qué campaña militar romana se refiere Jerónimo ${ }^{11}$. Llama la atención en estos textos patrísticos que el lugar de nacimiento del apóstol no era Tarso, como nos indica Hch 22,3, sino Gischala. Cómo y por qué se asentó la familia de Pablo en Tarso, son interrogantes a los que no se puede responder dados los insuficientes datos que las fuentes nos transmiten. Algunos autores opinan que los familiares del apóstol fueron conducidos a Tarso como escla-

este autor: "Aunque Pablo nació en Tarso, fue en realidad en Jerusalén donde recibió su educación en la casa paterna" (p. 301). Cfr. idem, Once again: Tarsus or Jerusalem, in: idem., Sparsa I 321-327.

8. P. van Minnen, "Paul" 49ss.

9. J.C. Lentz, Portrait 56, se muestra excéptico sobre este punto : "Que existieran judíos fariseos en Tarso es poco probable... Sin embargo, que Pablo haya nacido en una familia farisea en Tarso y que también poseyera la ciudadanía de esa ciudad griega... es altamente improbable".

10. Jerónimo, De viris illustribus 5 (Migne PL 23, col. 616); Comm in Phlm (Migne PL 26, col. 617.).

11. Existen dos posibilidades: una sería la campaña de Pompeyo en el año 63 a.C., y la otra la de Quintilio Varo en el año 4 a.C. (Josefo, BJ II 39-79). En el cerco y saqueo de Jerusalén llevado a cabo por Sosio (40-36 a.C.) no se menciona que algunos judíos fueran vendidos como esclavos (Josefo, BJ I 18,1ss). Por motivos cronológicos no se puede referir a la campaña de Vespasiano y Tito en el año 70 d.C. 
vos y vendidos allí. Posteriormente el padre habría adquirido como liberto la ciudadanía de dicha ciudad ${ }^{12}$. Otros exégetas, por el contrario, opinan que la familia, visto el cariz que tomaban los acontecimientos en Galilea y la situación política peligrosa, decidió huir antes de que fuera demasiado tarde y se asentó en Tarso ${ }^{13}$. En general, se puede decir que la tradición transmitida por Jerónimo es poco fiable y problemática.

Si el padre de Pablo obtuvo la ciudadanía de la ciudad de Tarso, se nos plantea el interrogante de cómo la consiguió. Para la adquisición de dicha ciudadanía se presupone un cierto prestigio y prosperidad económica. Con acierto subraya $K$. Haacker que el hecho de que Pablo hubiera sido enviado a Jerusalén para su formación indica claramente su proveniencia de una familia pudiente, con recursos económicos para poder financiar sus estudios ${ }^{14}$. En este sentido también se podría interpretar la noticia de que Pablo estaba en condiciones de asumir los costes que conllevaba el que cuatro hombres pudieran cumplir sus votos (Hch 21,24ss; los sacrificios impuestos para la conclusión del nazireato, $\mathrm{Nm} 6,14-15$, eran muy costosos). No es imposible que los antepasados hubieran comprado la ciudadanía de la ciudad de Tarso ${ }^{15}$.

Dentro del campo religioso, la posesión de la ciudadanía de una polis griega constituía un difícil problema para los judíos practicantes, dado que esa civitas conllevaba algunas exigencias con la sociedad y con los dioses de la ciudad, las cuales eran incompatibles con las creencias judías. Según algunos autores la adquisición de la ciudadanía de una polis griega era casi equivalente al abandono del judaísmo ${ }^{16}$. Dos alternativas se han presentado para intentar solucionar esta dificultad: $1^{\circ}$ Los judíos eran tan numerosos en Tarso que constituían una propia $\phi \cup \lambda \eta ́$ judía. Pero por desgracia no tenemos cono-

12. G. Kehnscherper, "Apostel” 420s; R. Riesner, Frühzeit 136.

13. K. Haacker, "Werdegang" 830.

14. Ibidem 831. La actividad manual de Pablo (fabricante de tiendas, Hch 18,3) no se puede aducir como prueba contra la prosperidad económica de la familia en tiempos de la adquisición de la ciudadanía. La familia podría haber sufrido posteriormente una decadencia económica. La renuncia a la posesión de bienes por parte de Pablo se podría explicar también por causas éticas cristianas, es decir, vivencia de una probreza voluntaria.

15. Ampliamente defienden la posesión de la ciudadanía de Tarso B. Doer, "Civis" 4969; M. Woloch, St. Paul's Two Citizenships, in: Helikon 11/12 (1971-72) 452-454. M. Hengel, "Paulus" 188-193, estima como probable que la familia de Pablo adquiriera la ciudadanía de Tarso mediante su compra.

16. Ver la discusión sobre la exención por parte de los judíos del culto de los dioses de la ciudad en Josefo, AJ XII 125ss. E.M. Smallwood, Jews 235, califica a los judíos que poseían la ciudadanía de alguna ciudad griega como "no menos que apóstatas". J.C. Lentz, Portrait 43, considera casi imposible que un fariseo pudiera poseer la ciudadanía griega: "Esos judíos que obtuvieron la ciudadanía, difícilmente se podrían llamar judíos fariseos estrictos. Tal vez 
cimiento del número de judíos que podían vivir en esa ciudad ni de la existencia de una $\phi v \lambda \eta ́$ judía. $2^{\circ}$ Había siempre arreglos individuales, sobre todo cuando se trataba de judíos ricos ${ }^{17}$. W. Stegemann considera como única posibilidad para explicar la ciudadanía de Tarso del apóstol, si no se quiere poner en duda su historicidad, que se había concedido a Pablo o a su padre la ciudadanía honorífica, la cual sin embargo no pusieron en práctica. De otro modo tendríamos que suponer que Pablo había ofrecido sacrificios o venerado a los dioses de la ciudad, lo cual es más difícil de aceptar ${ }^{18}$. M. Hengel cree

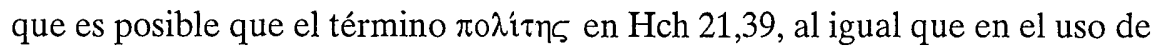
la Septuaginta $(\operatorname{Pr} 11,9 ; 24,28)$, pudiera indicar no la posesión de la ciudadanía jurídica sino más bien su origen ${ }^{19}$.

Según las consideraciones expuestas anteriormente habría que concluir diciendo que la posesión de la ciudadanía de Tarso tenía que ser muy problemática para un fariseo como Pablo por los compromisos ciudadanos y religiosos a los que iba unida ${ }^{20}$, aunque era posible. Por tanto, creo que debe permanecer abierta la cuestión de si Pablo era un ciudadano de Tarso.

\section{2.- Pablo como civis romanus ${ }^{21}$}

Según el texto de Hechos, Pablo poseyó una doble ciudadanía: la romana y la de la ciudad de Tarso. En el período julio-claudiano parece ser que la

se consideraban a sí mismos como leales al judaísmo. Sin embargo, habría sido sumamente difícil para un judío estricto y apegado a la ley, aceptar la ciudadanía con sus correspondientes obligaciones". Contra esta tesis afirma B. Rapske, Book 77: "Ciudadanía y religiosidad judía no eran mutuamente excluyentes".

17. J. Mélèze-Modrzejewski, “Tourments” 324s.; R. Riesner, Frühzeit 131.

18. W. Stegemann, "Apostel" 221.

19. M. Hengel, "Paulus" 191; R. Riesner, Frühzeit 131.

20. J.C. Lentz, Portrait 24, opina que la ciudadanía de Tarso habría sido incluso más problemática por sus distintas obligaciones sociales y civiles que la ciudadanía romana.

21. Otros artículos sobre la ciudadanía romana de Pablo, los cuales no he podido consultar: H.J. Cadbury, Roman Law and the Trial of Paul, in: F.J. Foakes-Jackson - K. Lake, Beginnings, vol. 5,297-338; H. Rosin, Civis Romanus sum, in: NedThT 3 (1948/49) 16-27; J. Schwarz, A propos du statut personnel de l'apôtre Paul, in: RHPhR 37 (1957) 91-96; E. Brewer, Roman Citizenship and Its Bearing on the Book of Acts, in: RestQ 4 (1960) 205-219; G. Lombardi, Motivi giuridici dell'appello di Paolo a Cesare, in: B. Mariani, S. Paolo da Cesarea a Roma. Esegesi, storia, topografia, archeologia, Roma 1963, 9-20; M. Carrez, L'appel de Paul à César (Ac 25,11): La double appartenance, juive et chrétienne, de la première Église d'après le livre des Actes, in: $M$. Carrez - J. Doré - P. Grelot (eds.), De la Tôrah au Messie, FS. H. Cazelles, Tournai 1981, 503-510; J. Vogt, Der Apostel Paulus als römischer Bürger, in: Universitas 36 (1981) 145-152; S. Légasse, L'apologétique à l'égard de Rome dans 
ciudadanía romana no excluía la posesión de la ciudadanía de otra ciudad, como había sido el caso en el tiempo de la república romana22. Aquí no analizaremos cómo el padre de Pablo (Hch 22,29: "yo tengo la ciudadanía desde el nacimiento") habría podido adquirir la ciudadanía romana, pues esa cuestión plantea los mismos interrogantes y dificultades que la adquisición de la ciudadanía de la ciudad de Tarso ${ }^{23}$. Simplemente sea dicho de paso que la mayoría de los estudiosos propone la manumisión ${ }^{24}$ como el camino más probable para la obtención de la ciudadanía romana. Otros interrogantes, como si Pablo dominaba el latín, o si tenía uno o tres nombres (típico entre los romanos $)^{25}$, tampoco serán estudiados en este artículo.

La ciudadanía romana se adquiría ${ }^{26:}$ a) por nacimiento; b) por manumisión; c) por ley, y d) por concesión del derecho de ciudadanía, donatio civitatis, individual o colectivo, concedido por el Senado o por el Emperador, a causa de leyes especiales, como podía ser después de prestar un servicio de

le procès de Paul, Actes 21,27-26,32, in: RSR 69 (1981) 249-255; H.W. Tajra, L'appel à César: séparation d'avec le Christianisme, in: ETR 56 (1981) 593-598; M. Black, Paul and Roman Law in Acts, in: RQ 24 (1981) 209-218; A. Keaveney, Civis Romanus sum, in: Critica Storica 21 (1984) 345-372.

22. Entorno al problema de la doble ciudadanía véase: W.W. Tarn, Kultur der hellenistischen Welt, Darmstadt 1966, 264; un buen estudio ofrece D. Nörr, Origo. Studien zur Orts, Stadt- und Reichszugehörigkeit in der Antike, in: TRG 31 (1963) 525-600; cfr. E. Ferenzcy, Bemerkungen 1046-1053; A.N. Sherwin-White, Citizenship 51-53.

23. Con razón afirma $B$. Rapske, Book 86 , que todas las suposiciones para la explicación de cómo la familia de Pablo había adquirido la ciudadanía romana son meras especulaciones.

24. La manumisión es el acto por el cual el dueño da la libertad al esclavo. Según J. Arias Ramos - J.A. Arias Bonet, Derecho Romano, vol. 1, Madrid, ${ }^{15} 1979,65 \mathrm{ss}$, ésta presentaba dos grupos de modalidades: manumisiones solemnes y no solemnes. Los manumitidos por un medio solemnes adquirían la ciudadanía romana juntamente con la libertad.

25. El uso ilegal del tria nomina romano fue considerado por Claudio como sancionable, cfr. Suetonio, Claud. 25. Sobre el problema del nombre cfr. A.N. Sherwin-White, Law 152ss. $K$. Haacker, "Werdegang" 834, subraya acertadamente que la no mención del nombre completo del apóstol en Hechos no constituye ningún argumento contra la posible posesión de la ciudadanía romana, porque en el NT no se encuentra ningún nombre romano completo, tampoco el de las personas de las cuales no existe duda alguna de su ciudadanía, como es el caso de los Emperadores, miembros de familias senatoriales y de los equestres, así como parientes de la casa de Herodes. Cfr. G.H.R. Horsley, The Use of the Double Name, in: idem., New Documents Illustrating Early Christianity. A Review of the Greek Inscriptions and Papyri, vol. 1, Macquarie University, North Ryde 1981, 89-96; C.J. Hemer, The Name of Paul, in: TynB 36 (1985) 179-183; T.J. Leary, Paul's Improper Name, in: NTS 38 (1992) 467-469; J. MurphyO'Connor, Paul 41-44.

26. Información fundamental sobre este tema se encuentra en E. Kornemann, Civitas, in: PRE.S 1 (1903) 304-317; F. Vittinghoff, Römische Kolonisation und Bürgerrechtspolitik unter Caesar und Augustus (AAWLM 14), Wiesbaden 1952; A.N. Sherwin-White, Citizenship; H. Galsterer, Civitas, in: DNP 2 (1997) 1224-1226. 
25 años en las tropas auxiliares romanas. Unido a la posesión de la ciudadanía romana estaban ligados privilegios en relación al derecho privado, procesal y estatal: derechos (derecho para elegir, exención de castigos corporales, el derecho provocationis o reiectio) y obligaciones (impuestos y servicio militar). Sólo los ciudadanos podían llegar a gozar de todos los derechos. La condición jurídica del ciudadano se puede sintetizar diciendo que, en el orden político, los ciudadanos tenían: el ius honorum (derecho al desempeño de cargos públicos), el ius suffragii (voto en las asambleas) y el derecho de servir en las legiones. Y en el orden privado: el ius conubii (derecho a contraer matrimonio y constituir una familia), el ius commercii (tenencia de derechos patrimoniales y celebración de actos relacionadas con ellos) y el ius actionis (facultad de acudir a los tribunales). En la esfera religiosa: el ius sacrorum (asociación dedicada al culto de la ciudad); el ius auspiciorum (derecho a tomar los auspicios) y el ius sacerdotii (derecho de ocupar los sacerdocios nacionales). Algunos judíos, tanto en Jerusalén como también en Roma y en Asia Menor, entre los cuales se supone a Pablo y a su padre, poseían la ciudadanía romana y gozaban de privilegios durante el período julio-claudiano.

Según las leyes romanas (Lex Iulia de vi Publica, Lex Valeria y Lex Porciae ${ }^{27}$ ) no estaba permitido que un ciudadano romano fuera atado o azotado por mandato de un magistrado (adversus provocationem). La ciudadanía romana era un status personal que ofrecía protección jurídica contra un posible abuso de poder por parte de los magistrados. E.A. Judge y J.C. Lentz ponen de relieve que en la aplicación de la justicia y del derecho romano a los ciudadanos del siglo I d. C. existía más flexibilidad 28 de la que normalmente se supone y frecuentemente se actuaba en contra del derecho en vigor. Por otra parte, la infracción de las leyes anteriormente citadas podía ser castigada severamente ${ }^{29}$.

Lucas menciona en tres ocasiones la ciudadanía romana de Pablo, a la que el evangelista da mucha importancia. La pregunta que ahora tenemos que responder es si la tradición lucana es histórica o más bien una construc-

27. Cfr. Lex Valeria: Cicerón, rep II 54; Livio, X 9. Lex Iulia: Ulpiano, Dig 48,6,7; Maecianus, Dig 48,6,8; Paulo, Sent V 26,1s.

28. E.A. Judge, Rank and Status in the World of the Caesars and St. Paul (University of Canterbury Publications 29), Canterbury 1982, 12s; J.C. Lentz, Portrait 124-130. Cfr. los ejemplos de ejecuciones y castigos corporales de ciudadanos romanos: Josefo, BJ II 306-308 (crucifixión de algunos judíos romanos pertenecientes a la clase equestre); Suetonio, Galb. 9; otros ejemplos se encuentran en $P$. Garnsey, "Lex" 174-176.

29. Los habitantes de Rhodos ( Po $\delta^{\prime} i \omega v$ ) fueron severamente castigados y perdieron su status privilegiado por haber ejecutado a un ciudadano romano (Dion Casio, LX 24,4).

30. Así opina E. Haenchen, Apg 443; B. Rapske, Book 115-134, especialmente 130ss. El 
ción del evangelista que cuadra muy bien con sus intenciones teológicas y propagandistas de Hechos. La mayoría de los exégetas e historiadores afirman la historicidad de la información transmitida por Lucas. W. Stegemann ha estudiado nuevamente el problema desde diversas perspectivas así como la problemática que plantea la tradición transmitida por Lucas, y llega a la conclusión de que Pablo no era un ciudadano romano. Veamos algunos de sus argumentos más importantes.

\subsection{La ciudadanía romana del apóstol en Hechos y su apelación al César}

En primer lugar serán analizados los testimonios directos de Hechos de los Apóstoles que afirman la ciudadanía romana. La primera mención que encontramos es en el caso de Filipos. Sabemos que Pablo tuvo conflictos en esa ciudad con las autoridades romanas. La presentación de Hch 16,37 no es estructuralmente lógica. La apelación a la ciudadanía tiene lugar después que Pablo y Silas ya habían sido azotados públicamente por los lictores y arrojados a la cárcel. Lo lógico hubiera sido que los dos apóstoles hubieran dado a conocer su ciudadanía romana a los magistrados cuando fueron arrastrados (v. 21). Los estudiosos han intentado superar esta dificultad mediante dos hipótesis: $1^{\circ}$ Pablo apeló a su status de ciudadano, el cual sin embargo fue ignorado. Esta explicación no es convincente: si Pablo ya había dado a conocer su ciudadanía, entonces no se entiende el hecho de que a los pretores les entrara miedo al día siguiente cuando oyeron que los azotados eran romanos. $2^{\circ}$ Pablo no apeló a su ciudadanía, pues dicha apelación le habría librado de los latigazos, pero le habría implicado en un largo y difícil proceso jurídico con una resolución incierta para él ${ }^{30}$. El miedo de los pretores es sólo comprensible cuando el magistrado hubiera ordenado el castigo corporal teniendo pleno conocimiento de la posesión de la ciudadanía del apóstol31. Y si Pablo quería que su status permaneciera en secreto, ¿por qué entonces apela a su ciudadanía después del castigo y da a conocer su situación jurídica? Eso sería una contradicción. Por tanto, los dos intentos de explicación no solu-

30. Así opina E. Haenchen, Apg 443; B. Rapske, Book 115-134, especialmente 130ss. El menciona otros motivos religiosos y económicos para el silencio de Pablo. "Una apelación prematura habría causado también importantes consecuencias negativas para su misión" (pg. 134).

31. Sobre el miedo como motivo literario y teológico cfr. T. Hosaka, Lukas und das Imperium Romanum unter besonderer Berücksichtigung der literarischen Funktion des Furchtmotives, in: AJBI 14 (1988) 82-134. 
cionan la dificultad que hemos planteado. W. Stegemann ${ }^{32}$ concluye que el episodio de Filipos originalmente no contenía ninguna indicación de la ciudadanía de Pablo.

El segundo texto que afirma la posesión de la ciudadanía romana es Hch 22,22-29. Pablo deja bien claro ante el tribuno Claudio Lisias su conocimiento del lenguaje griego (el conocimiento del latín o del griego era uno de los requisitos para la obtención de la ciudadanía romana) ${ }^{33}$ y declara que es ciudadano de una ciudad importante de Asia Menor (Hch 21,39). El tribuno ordena introducir a Pablo en la torre Antonia a causa de los tumultos causados por los judíos y someterlo a torturas para averiguar por qué motivo los judíos gritaban contra él. Cuando todo estaba preparado para fustigarlo, Pablo se dirige al centurión con la pregunta retórica: “¿Os es lícito azotar a un ciudadano romano sin haberle juzgado?" (Hch 22,25). Avisaron al tribuno y éste se informó de que Pablo poseía la ciudadanía romana desde su nacimiento, mientras que él mismo, un alto dignatario militar de Roma en Jerusalén, había tenido que pagar un alto precio para obtenerla (seguramente mediante soborno) ${ }^{34}$. El tribuno temió al darse cuenta que le había encadenado siendo romano (v. 29). ¿Por qué no se dio a conocer Pablo como ciudadano romano cuando lo apresaron? ${ }^{35}$ ¿Quería el evangelista aumentar el

32. W. Stegemann, “Apostel” 202.

33. Suetonio, Claud. 16 y Dion Casio, LX 17,5 relatan que Claudio condicionaba la concesión de la ciudadanía al cumplimiento de algunos requisitos entre los que se encontraban el dominio de la lengua latina. Sobre la política de Claudio referente a la concesión de la ciudadanía cfr. T. Mommsen, Edikt des Kaisers Claudius über das römische Bürgerrecht der Anuaner vom J. 46 n.Chr., in: Hermes 4 (1870) 99-131; U. Schillinger-Häfele, Das Edikt des Claudius CIL V 5050 (Edictum e civitate Anaunorum), in: Hermes 95 (1967) 353-365; sobre la concesión de la ciudadanía a la aristocracia gala cfr. Tácito, ann. 11,23,1. A.N. SherwinWhite, Citizenship 237-250; idem, The Roman Citizenschip. A survey of its development into a world franchise, in: ANRW I 2 (1972) 23-58; S. Demougin, Claude et la société de son temps, in: V.M. Strocka (Hrsg.), Regierungszeit des Kaisers Claudius (41-54 n.Chr.). Umbruch oder Episode? Internationales interdisziplinäres Symposium aus Anlaß des hundertjährigen Jubiläums des Archäologischen Instituts der Universität Freiburg i. Br. 16.-18. Februar 1991, Mainz 1994, 11-22.

34. El tribuno había comprado la ciudadanía en tiempos de Claudio. Seneca, apocol. 3,3 y Dion Casio, LX 17,1 afirman que la civitas romana se había convertido accesible a todo el mundo en tiempos de Claudio, dado que se podía adquirir fácilmente. Culpable de esta situación no era el Emperador mismo, sino más bien los funcionarios corruptos (Tácito, ann. $14,50,1)$ que traficaban con cargos y privilegios. Cfr. B. Holtheide, Bürgerrechtspolitik 55s, quien confirma la política activa de este Emperador para otorgar la ciudadanía mediante la extensión del nombre gentilicio "Claudius" en Asia Menor.

35. B. Rapske, Book 143, menciona como motivo: "Pablo no insistirá tanto en sus derechos romanos para no socavar su compromiso religioso con el judaísmo ante los ojos romanos". 
suspense con esta presentación?36. Según W. Stegemann esta tensión escalonada y progresiva de los acontecimiento es sin lugar a dudas obra del narrador de $\mathrm{Hechos}^{37}$. De esta mención de la ciudadanía romana del apóstol depende en último lugar la noticia posterior en Hch 23,27.

Una vez presentados los textos directos que hablan de nuestro tema nos quedan por analizar los testimonios indirectos. En Hch 28,18 el narrador resume brevemente la situación y las causas de la prisión de Pablo: los romanos habían querido dejar libre a Pablo después de haber investigado su caso y no haber encontrado nada que fuera digno de mantenerlo en prisión. Pero como los judíos se oponían, se vio obligado a apelar al César. Por el contrario, las circunstancias en la escena de apelación vienen presentadas de forma distinta: Festo le propone un cambio de instancia jurídica. En lugar de un tribunal imperial en Cesárea ante el cual estaba Pablo, le propone un juicio ante una instancia judía en Jerusalén y bajo su supervisión (Hch 25,9ss) ${ }^{38}$. Según el mismo Agripa (Hch 26,31), Pablo no había cometido ningún delito para estar en prisión ("Podía ser puesto en libertad este hombre si no hubiera apelado al César"). Pablo apela al César en el transcurso del proceso legal ante el Procurador Festo, dado que el apóstol no se fiaba de la imparcialidad y objetividad del Procurador. El apóstol en este caso no hace mención expresa de la posesión de su ciudadanía romana, pero según la presentación lucana es de suponer que sólo la ciudadanía romana del imputado es el presupuesto jurídico para su apelación.

El derecho de apelación ${ }^{39}$ (provocatio, es decir, la apelación después del fallo de la sentencia, o reiectio, la no aceptación del juicio antes de que haya sido pronunciado el veredicto) en el primer período del principado es tan complejo y problemático, que se ha intentado aclarar con los datos que nos transmite Hechos. La apelación del apóstol suscita, sin embargo, más interrogantes que respuestas, por lo que se ha puesto en tela de juicio la histori-

36. Cfr. las preguntas que plantea W. Stegemann, “Apostel” 205: “¿Por qué permite que el juicio se celebre ante el Sanedrín de Jerusalén, cuando éste no era competente para juzgar a ciudadano romano? ¿Por qué el tribuno militar no dejó libre a Pablo cuando se enteró de que era un ciudadano romano? ¿Podía y debía convocar el Sanedrín incluso para proceder jurídicamente contra un romano?".

37. W. Stegemann, "Apostel" 205.

38. Cfr. H.W. Tajra, Trial; W.R. Long, The Trial of Paul in the Book of Acts: Historical and theological Consideration, (Ph. D.) Brown University 1982.

39. La apelación tenía como objetivo fundamental subsanar decisiones judiciales defectuosas (recurrir sentencias incorrectas). Poseemos información sobre la apelación en tiempo de Claudio (Suetonio, Claud. 12,1;14;15;29,1; Tácito, ann. 12,60) y de Nerón (Suetonio, Nero 17; Tacito, ann. 14,28). Sobre el derecho de apelación ver J. Bleicken, Senatsgericht 54ss; $A$.W. Lintott, "Provocatio" 226-267. 
cidad y funcionamiento jurídico de los pasajes lucanos ${ }^{40}$. El caso presenta un problema jurídico sin solución dado que los documentos y las fuentes jurídicas no son claras como para pronunciarnos al respecto41. Lo ilógico de la composición y presentación lucana está no sólo en la oscura explicación para justificar la apelación, sino también en el hecho de que Pablo apela a la mayor instancia de los tribunales romanos antes de que el Procurador haya emitido su veredicto ${ }^{42}$. Otros problemas de la composición lucana son, por ejemplo, la propuesta de Festo de cambiar la instancia jurídica que se encarga del juicio43: el interrogatorio de un romano, Pablo, por un tribunal judío (el Senedrín), el cual era una instancia local religiosa y, en parte, jurídica para los judíos, pero de ningún modo tenía jurisdicción sobre ciudadanos romanos. El único tribunal competente para solucionar el caso de Pablo era un tribunal imperial. Sin embargo, Festo deja al mismo presunto culpable la decisión de si quiere regresar a Jerusalén o no.

Los pruebas de acusación que jugaron un papel importante en el contencioso contra Pablo se pueden deducir de la presentación que Lucas nos da del proceso legal ante el Procurador Félix. Allí Tértulo, abogado demandante, junto con otros judíos presentaron ante el Procurador la acusación difamatoria contra Pablo: éste es una peste que provoca altercados entre los judíos de toda la tierra y es el jefe principal de la secta de los nazoreos (Hch 24, 5). Tértulo hace referencia a las circunstancias en que el apóstol fue apresado en Jerusalén: Pablo había intentado profanar el templo. Félix pospuso el caso y será su sucesor, Porcio Festo, quien al inicio de su mandato reabra el proceso. El nuevo Procurador no tiene dudas de que se trata de un problema religioso interno judío y sin dimensiones políticas ${ }^{44}$. Un difícil problema en este proceso jurídico se nos plantea en la afirmación del Procurador, cuando

40. Para la discusión sobre este caso provocatio o reiectio, cfr. A.H.M. Jones, I appeal unto Caesar, in: idem., Studies in Roman Government and Law, Oxford 1960, 51-65; P. Garsney, "Lex" 182-185; A.W. Lintott, "Provocatio" 226-267; J.C. Lentz, Portrait 144-153.

41. Véase J.C. Lentz, Portrait 141.

42. E. Haenchen, Apg 596s, constata diversas dificultades y anomalías en el proceso y lo considera como resultado de una composición lucana. Según $A$. Suhl, Paulus 295, nota 69, la falta de claridad y la confusión del relato lucano indican que Lucas reelaboró aquí una fuente, que éste no entendió con claridad.

43. P. Garnsey, "Lex" 184, y K. Haacker, "Werdegang" 838, argumentan contra la posibilidad de que el gobernador pudiera constituir su consilium con los miembros del Sanedrín durante el juicio en Jerusaläen.

44.J. Mélèze-Modrzejewski, "Tourments" 334, entiende la acusación religiosa contra Pablo de la siguiente forma: La profanación del templo es el único punto de acusación claramente formulado. Pero esto no era ningún "delito" según las categorías romanas. Si hubiera 
admite la inocencia de Pablo (Hch 25,25ss; 26,32) y, a pesar de ello, permite que un ciudadano romano siga en prisión. Con razón W. Schmithals ${ }^{45}$ plantea la pregunta, si un Procurador podía enviar ante el César a un acusado cuya inocencia ya había sido demostrada. Lo lógico sería afirmar que no.

Tampoco es claro por qué Pablo apeló al Emperador. Él se encontraba en una situación en que su vida corría verdadero peligro y desconfiaba de una sentencia imparcial del tribunal46. Si estos fueron los motivos para su apelación, como normalmente se ha presupuesto, entonces tenemos que suponer que el apóstol ya habría apelado al César en otras ocasiones en el transcurso de su vida y que habría intentado hacer valer su ciudadanía romana. Sabemos que Pablo estuvo preso en Éfeso (Flp 1,7.13s.17; Flm 1,1.9.13; 2 Cor 4,7-14), y que en esa ocasión temió por su vida ( 2 Cor $1,8 \mathrm{~s}$ ). Él ya había perdido la esperanza y daba por hecho la sentencia condenatoria. El empleo del termi-

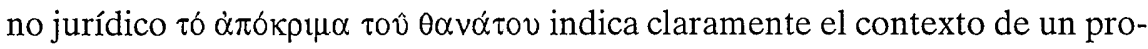
ceso en el que Pablo consideraba a la autoridad romana como una instancia amenazadora de muerte ( 2 Cor 1,9; Flp 1,13.20). En este caso, nos podemos preguntar si Pablo ya había apelado en Éfeso en esas circunstancias adversas $^{47}$, si las autoridades romanas rechazaron dicha apelación, o si Pablo no había podido demostrar su ciudadanía romana ${ }^{48}$. ¿O no era posible la apelación durante el reinado del Emperador Claudio (41-54)? Sabemos que en tiempo de Calígula (37-41) existió temporalmente la prohibición de apelación al César contra la sentencia pronunciada por un magistrado. Una prohibición

sido un extranjero cualquiera, que la comunidad había detenido por desacato de la prohibición de pisar el templo, entonces la autoridad romana habría hecho la vista gorda. Pero ¿cómo podía castigar a un ciudadano romano por haber ayudado a un intruso a traspasar los umbrales del templo judío, cuando los templos romanos estaban abiertos a todos? La autoridad romana se encontraba ante un problema sin solución.

45. W. Schmithals, Apg 219.

46. Cfr. la variante de Hch 28,19 en algunos manuscritos (614.2147...): $\alpha \lambda \lambda^{\prime}$ iv $\alpha \lambda v \tau \rho \omega \sigma \omega$ $\mu \alpha \imath \tau \eta v \psi v \chi \eta \nu \mu \circ v \varepsilon \kappa \theta \alpha v \alpha \tau o v$.

47. J.-F. Collange, Phil 26, opina que Pablo decidió apelar a su ciudadanía romana después de un tiempo en prisión. 2 Cor 1,9s sin embargo no permite esta conclusión. Otros exégetas defienden que no fue Pablo, sino los cristianos de Éfeso quienes dieron a conocer su nacionalidad ante las autoridades competentes; según $M$. Carrez, "Note" 776, Pablo estuvo en una situación de peligro de muerte en el proconsulado de J. Silanus y pudo ser liberado de forma inexperada gracias a la muerte de este procónsul (Tácito, ann. 13,1). Amigos adinerados e influyentes pudieron comprar su liberación. Pablo mismo, sin embargo, no apeló a su status romano.

48. Se tenía que llevar consigo una copia de la professio o diplomata original (es decir, un documento o un certificado) para demostrar la ciudadanía. Véase para ello A.N. SherwinWhite, Society 149. Es posible que Pablo hubiera perdido una vez ese certificado en alguno de sus viajes, pero que los perdiera en tres ocasiones ( 2 Cor 11$)$ parece un poco exagerado. 
de apelación en tiempos de Claudio no es segura (Tácito, ann. 12,60; Suetonio, Claud 12). Por desgracia no poseemos una información más precisa sobre el caso del apóstol en Éfeso. Tal vez el texto de 1 Cor 15,32 indique también una amenaza mortal, cuando Pablo habla de una lucha contra las bestias en Éfeso. Pero un romano no podía ser arrojado a las bestias. Se ha intentado dar una posible explicación mediante una noticia que transmite Gayo, Digesta XXVIII 1,8,4, según la cual habría algunos delitos que se podían castigar con la pérdida de la ciudadanía, y por tanto se podrían aplicar castigos que normalmente no eran permitidos para los romanos. Pero en el caso de Pablo, Hch 22,25 presupone que el apóstol todavía era ciudadano. Que hubiera perdido su ciudadanía y posteriormente la hubiera vuelto a recuperar, es más que improbable.

\section{2.- Argumentos contra de la posesión de la ciudadanía romana en las cartas del apóstol}

Los castigos corporales que Pablo dice haber sufrido, son sin lugar a dudas la prueba más feaciente en las cartas del apóstol para concluir que éste difícilmente pudo haber poseído la ciudadanía romana. Según 1 Ts 2,2, Pablo

padeció injurias y sufrimientos en Filipos. Teóricamente podría referirse aquí a malos tratos infringidos por personas privadas. Más explícito es el pasaje de 2 Cor 11,24ss. Según este texto Pablo sufrió cinco veces el castigo sinagogal judío de la flagelación ${ }^{49}$, y en tres ocasiones fue azotado oficialmente (por funcionarios estatales o de la ciudad). En estrecha conexión con estos castigos, Pablo también menciona en 2 Cor 11,23 y en 2 Cor 6,5 su reclusión carcelaria. ¡Los ciudadanos romanos estaban oficialmente protegidos contra el encadenamiento y contra castigos corporales 50 ! El azotamiento mencionado en Hch 16,22s y llevado a cabo por los lictores era por tanto ilegal, lo mismo que los zurriagazos de 2 Cor 11,25. Aunque se acepte que las correspondientes leyes no siempre se cumplían al pie de la letra, la triple infracción de la norma contra la misma persona debía ser un caso muy raro. Por lo demás,

49. Véase $S$. Gallas, "Fünfmal vierzig weniger einen...". Die an Paulus vollzogenen Synagogalstrafen nach 2 Kor 11,24, in: ZNW 81 (1990) 178-191.

50. Livio, X 9,4; Cicerón, Rab. Post 4,12f.; Appiano, Civ II 26,98; Paulus, Sent V 26,1; Ulpiano, Dig 48,6,7; A.N. Sherwin-White, Society 57ss. P. Garnsey, "Lex" 167-189, diferencia los siguientes castigos corporales: fustes (aplicado a los hombres libres) y flagella (para los esclavos), admonitio o castigatio (latigazos suaves), verberatio y pulsatio. Cfr. W. Eisenhut, Die römische Gefängnisstrafe, in: ANRW I 2 (1972) 268ss. 
Pablo sería el único ciudadano romano conocido, que estuvo dispuesto a someterse en cinco ocasiones al castigo de la flagelación sinagogal, cuando la sinagoga no era un órgano jurídico que tuviera jurisdicción sobre él. Este castigo deshonroso y cruel se lo podría haber evitado fácilmente si era ciudadano romano. "Todo esto podría haber sucedido sólo libre y voluntariamente y si tenía tendencias masoquistas"51. R. Riesner opina, por el contrario, que dicha diagnosis psicopatológica moderna no se podría aplicar a Pablo, sino que el apóstol habría interpretado todos los malos tratos sufridos desde el significado del sufrimiento de Cristo52. Pero si Pablo había entendido así sus sufrimientos y dolores, entonces se plantea la cuestión, según mi opinión, ¿por qué Pablo apeló ante Festo al Emperador y no quiso aceptar otra vez más los malos tratos infringidos por los judíos e interpretarlos como una forma de participar de los sufrimientos de Cristo? Si Pablo quería ir a Roma (Hch 19,21) y llegar hasta allí como un "justo sufriente" para anunciar el evangelio en la misma capital del imperio (Lucas ya indica esto en Hch 1,8: la predicación del evangelio hasta los confines de la tierra), entonces podría haber llegado antes a su destino, si él hubiera apelado al César cuando fue castigado por primera vez por los romanos.

El triple castigo de los azotes del apóstol llevado a cabo por los romanos se ha intentado explicar de distintas formas. $1^{\circ} \mathrm{El}$ hecho de que Pablo fuera azotado indica simplemente que la ciudadanía romana sólo era una protección insuficiente contra magistrados crueles. Los castigos corporales de Pablo significarían, por tanto, que la Lex Iulia no se observaba ni permanente ni consecuentemente en el imperio. Pero si el no cumplimiento de dicha ley se había convertido en una "norma" habitual, entonces no se encuentra una respuesta adecuada para la pregunta, por qué a los magistrados de Filipos les entró el miedo (según la narración lucana) cuando se enteraron de la ciudadanía de Pablo. $2^{\circ}$ A.N. Sherwin-White ha propuesto otra tesis. Su interpretación se apoya en el supuesto desarrollo progresivo de las leyes que se refieren a la protección de los ciudadanos contra la coercitio de las autoridades romanas en tres fases. En un primer periodo estaba prohibido castigar a un romano; en un segundo momento (ya antes del reinado de Nerón) se aceptaron excepciones a esa praxis; en la tercera fase se diferenció definitivamente entre los honestiores y los humiliores a la hora del castigo. Sherwin-White opina que Pablo protesta en Filipos no contra el hecho de que él haya sido azotado, sino que haya sido castigado sin haber sido anteriormente juzgado y

51. W. Stegemann, "Anfragen" 485.

52. R. Riesner, Frühzeit 133. 
condenado. Esta interpretación presupone que las autoridades de una provincia romana podían aplicar el castigo corporal después del fallo del juicio en caso de que el ciudadano romano no apelara o cuando se tratara de un caso muy especial que no era contemplado en la Lex Iulia. El hecho de que Pablo mencione en 2 Cor el castigo romano significa que el apóstol fue condenado en las tres ocasiones por las autoridades romanas y que fue castigado en conformidad con la ley. Este castigo legal del apóstol correspondería según Sherwin-White a la segunda fase del desarrollo de la ley.

Esta teoría53, según la cual en el primer siglo del principado los gobernadores romanos recibieron más poder para condenar delitos capitales sin provocatio, ha sido analizada y criticada por P. Garnsey. Este autor opina que los ejemplos aducidos por Sherwin-White no permiten afirmar que los gobernadores hicieran caso omiso de las apelaciones porque ellos hubieran obtenido una jurisdicción inapelable gracias a una ley adiccional; o bien somos testigos de un puro abuso de poder o el derecho de apelación no está en entredicho ${ }^{54}$. Esto significa que Pablo habría podido apelar al César en las tres ocasiones que fue castigado. Otra cosa distinta es la efectividad de la provocatio: "La eficacia de la apelación dependía de la discreción del gobernador. De hecho, la persona encargada en las provincias de juzgar los casos criminales tenía el poder, pero no el derecho, de rechazar una apelación contra su propia sen-

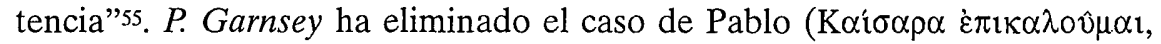
Hch 25,11) del campo jurídico de la apelación y lo ha colocado en la categoría de reiectio iudicii, el rechazo de los jueces por el acusado o una forma de juicio, que sostenía que estaba predispuesta contra él. $A$.W. Lintott ${ }^{56}$, por su parte, piensa que es preferible considerar la apelación de Pablo como ejemplo de una forma de recurso al auxilium de los tribunos antes que explicarlo mediante un supuesto principio general en la ley romana según la cual un acusado podía rechazar a todo un tribunal.

No hay que subestimar el problema religioso que planteaban a un judío las exigencias que conllevaba la ciudadanía romana. W. Stegemann ${ }^{57}$ indica que existía una incompatibilidad entre los derechos y exigencias de los roma-

53. A.N. Sherwin-White, Society 71-75.

54. P. Garnsey, "Lex" 176. C.J. Lentz, Portrait 135, afirma: "Donde Hechos no coincide fácilmente con las leyes, Sherwin-White parece dar por supuesto que tuvo haber cambios en la ley romana de modo que el testimonio de Hechos pueda acomodarse".

55. Ibidem, 167.

56. A.W. Lintott, "Provocatio" 265.

57. W. Stegemann, "Apostel" 224. Sobre los peligros de la ciudadanía romana para la religión judía cfr. L. Wenger, Bürgerrecht, in: RAC 2 (1954) 781s. 
nos y la religión judía: "La ciudadanía romana incluía la exigencia de ofrendas a los dioses romanos. Que los judíos en posesión de dicha ciudadanía estuvieran exentos de tales obligaciones no está probado". R. Riesner 58 ve en las exigencias normales de los ciudadanos romanos un peligro para la desviación y la apostasía del judaísmo. Pero que la posesión de la ciudadanía no equivalía a la apostasía nos lo testifica un pasaje del filósofo judío Filón (LegGai 156s) sobre algunos judíos en Roma, quienes poseían la ciudadanía romana y al mismo tiempo conservaban su religión. Otro pasaje de Tácito, ann. 2,85,4 apoya esta suposición. Parece ser que un judío, poseedor de dicha ciudadanía, podía mantenerse alejado de los cargos sacerdotales. Pablo, por tanto, como ciudadano romano no habría tenido la obligación de ponerse a disposición como augustales para el culto de la dea Roma y del divus Augustus en Tarso. No sabemos si el apóstol tuvo que prestar juramento por los Emperadores deificados y por el Emperador viviente (Nerón) ${ }^{59}$ ante el tribunal que lo juzgaba.

Dados los privilegios que tenían los judíos dentro del imperio romano, podemos suponer que los judíos con ciudadanía romana estaban exentos del culto al Emperador. Por tanto las "exigencias" (o mejor dicho, la presión impuesta por la sociedad y no por el Emperador) referentes al culto al Emperador no excluyen una posible posesión de la ciudadanía romana del apóstol, aunque para un fariseo sería más que improbable. El texto paulino 2 Cor 11,22ss, parece indicar, según mi opinión, que Pablo no poseyó dicha ciudadanía. Pablo habla en esa carta sobre todo a pagano-cristianos de una colonia romana (Colonia Laus Iulia Corinthiensis), en la cual la ciudadanía romana era muy estimada. Él se compara en dicho pasaje con misioneros enemigos judeocristianos, los cuales se consideran hebreos, israelitas, descendientes de Abraham y servidores de Cristo. No parece que fueran ciudadanos romanos. Lo mismo que el apóstol, ellos también sufrieron por causa del evangelio encarcelamientos y castigos corporales ${ }^{60}$, y se vanagloriaban de ello. Si Pablo hubiera sido un romano, tendría que haberlo dicho aquí como un argumento retórico en la confrontación con sus enemigos, de modo que se

58. R. Riesner, Frühzeit 133.

59. K. Haacker, "Werdegang" 839: "Ningún ciudadano estaba obligado a presentarse candidato para un puesto que conllevara acciones cúlticas. La obligación de prestar juramento en una declaración judicial según la fórmula pagana prescrita podía originar un casus confessionis. Este peligro pudo haber motivado que el apóstol no apelara a su ciudadanía sin ser necesario".

60. Pablo usa en dos ocasiones el comparativo $\pi \varepsilon \rho t \sigma \sigma o \tau \varepsilon \rho \omega \zeta ~(2$ Cor 11,23$)$ y reconoce con ello que también sus enemigos habían sufrido a causa del evangelio. 
convertiría en el clímax de su argumentación ante los pagano-cristianos de una ciudad romana. Mediante dicha mención habría podido convencer mejor a sus oyentes o lectores que él tenía más razones que sus adversarios para ser servidor de Cristo. El argumento ex silentio es siempre problemático a la hora de interpretarlo, pero que Pablo no adujera en su argumentación retórica su status civitatis es inexplicable en este contexto polémico61. También los testimonios paulinos sobre los castigos sufridos por el apóstol indican claramente que el apóstol no poseyó dicha ciudadanía.

La hipótesis según la cual Pablo habría apelado al nuevo Emperador Nerón, después de la muerte de Claudio (54 d. C.), con la esperanza de que ése dictara una sentencia favorable al apóstol, es históricamente improbable. Un ciudadano romano, que hubiera sido acusado de practicar religiones extranjeras ilícitas (collegia illicita), no podía esperar de Nerón ninguna sentencia más imparcial o favorable que de su predecesor Claudio. El acusado romano sería considerado como un traidor a las viejas tradiciones romanas. En este contexto hay que mencionar un texto del historiador romano Tácito, ann. 13,32,2. En el año 58 d. C. se inició un proceso jurídico contra una distinguida señora romana, Poponia Graecina, a quien se la acusó de practicar religiones extranjeras. La dama fue absuelta de cargos y puesta en libertad, pero el suceso documenta cómo la práctica de religiones orientales extranjeras, no reconocidas oficialmente por el estado, podía ser sospechosa y acarrear consecuencias nefastas para sus adeptos romanos. Si Pablo conoció este famoso caso, su apelación al Emperador habría supuesto por su parte la firma consciente de su propia condena. Otro argumento, que hace improbable que Pablo hubiera podido confiar en un desenlace positivo de la apelación a Nerón, sería el siguiente: Pablo había sido acusado por los judíos ante las autoridades romanas de Cesárea. El desenlace de una apelación a Nerón, sobre el cual los judíos podían influir a través de la emperatriz projudía y de Aliturus $^{62}$, un actor judío en la corte imperial, habría sido seguramente su

61. R. Riesner, Frühzeit 138, explica la no mención de la ciudadanía romana del apóstol en sus cartas por el hecho de que ninguno de sus escritos iba dirigido a ninguna autoridad romana o a un alto cargo. Pero éste no es argumento válido, dado que Pablo tampoco escribió ninguna a carta a fariseos, sino a paganacristianos, ante los cuales subraya su origen judío. G. Lüdemann, Christentum 249, piensa que Pablo no habría tenido la ocasión de haber mencionado su ciudadanía romana. Contra esa opinión se expresa $K$. Wengst, Pax 95.215, nota 29. Según este autor, la mención de su ciudadanía habría venido como anillo al dedo en ese contexto: "Que él no lo haya hecho, no excluye la posibilidad de su ciudadanía romana, subraya sin embargo, que en caso de que él la poseyera, no le otorgó mucha importancia" (pg. 95).

62. Los judíos de la ciudad de Roma tenían buenos contactos con la corte imperial. Josefo, Vit. 13-16, nos relata cómo la mujer de Nerón, Popea Sabina, era simpatizante de los judíos. Ver el texto más adelante. 
muerte. Por tanto habría sido más aconsejable para Pablo permanecer en Cesárea.

Se puede aducir otro argumento contra la tesis de que Pablo era un romano. Si consideramos que el texto de Rm 16,4 ("Saludad a Prisca y a Áquila..., quienes expusieron sus cabezas ${ }^{63}$ para salvarme") no es una glosa o un añadido posterior, sino un texto paulino auténtico, es incomprensible que Pablo hubiera arriesgado la vida de dos de sus mejores colaboradores, cuando él, como romano, hubiera podido sencillamente apelar al César. Si sus enemigos hubieran sido judíos, éstos no se habrían atrevido a matar a un ciudadano romano en la diáspora. ¿En qué ocasión arriesgaron Prisca y Áquila sus vidas por Pablo? No es posible dar una respuesta segura, pero los indicios apuntan a que ocurrió durante su estancia en Éfeso (1 Cor 15,32; 2 Cor 1,8s).

Contra la historicidad de la apelación al César por parte del apóstol se podría argumentar que Pablo no sería consecuente con sus ideas. En 1 Cor 6,2-8 el apóstol se opone explícitamente a que los cristianos recurran a los tribunales estatales. Según la concepción paulina, existen instancias estatales, pero éstas no son para los cristianos. ¿Por qué entonces apela Pablo en su proceso al Emperador?

Otro indicio que apoya la hipótesis de la no posesión de la nacionalidad romana por parte del apóstol es el influjo negativo que tuvo el edicto de Claudio del año 49 d.C. contra los judíos (PLond. 1912) en los planes de viajes del apóstol. Pablo concentró sus primeras actividades en Europa en las colonias romanas y siguió, según Hechos, la vía Egnatia, el camino terrestre más corto de oriente hacia Roma. Es muy probable que Pablo ya tuviera la idea de ir a Roma cuando fundó la comunidad de Tesalónica (Rm 1,10.13; $15,22)$ y fue en esta ciudad donde tuvo noticia por primera vez de los acontecimientos políticos de Roma y del decreto imperial por el cual se expulsaba a los instigadores judíos y cristianos de los disturbios. Dado que su vida corría peligro tuvo que abandonar precipitadamente la ciudad y se dirigió hacia el sur, hacia Corinto, con la esperanza de una rápida normalización de la situación política de Roma. Durante su estancia en Corinto le llegaron noticias procedentes de algunas comunidades paulinas sobre la misión cristiana antipaulina organizada por judeocristianos (véase Gálatas, Filipenses). Pablo intenta solucionar estas crisis. El edicto imperial frustró y desbarató su plan de viajar a Roma. Si Pablo hubiera sido un ciudadano romano, podría haber continuado su ruta prevista hacia Roma sin dificultades, dado que el edicto

63. Sobre esta expresión popular cfr. 1 Clem 63,1; A. Deissmann, Licht 94s. 
no estaba dirigido contra los romanos, sino sólo contra los judíos. Esta breve reconstrucción de los hechos históricos ${ }^{64}$ parece indicar más bien que Pablo era un judío y que como mucho poseería la ciudadanía de Tarso. Sólo después de la muerte de Claudio ( $54 \mathrm{~d}$. C) y de la derogación de su decreto vio el apóstol la posibilidad de cumplir su viejo sueño de ir a Roma.

\section{Resumen}

El resultado del estudio de los pasajes de Hechos nos ha mostrado que tanto la ciudadanía romana de Pablo como la apelación no son históricas, sino una construcción lucana. Esta conclusión pone en tela de juicio toda la presentación lucana del traslado de Pablo a Roma. Histórico, o como mucho posible, podría haber sido un tal traslado siempre y cuando los no ciudadanos romanos tuvieran también el derecho de apelación. Pero este no era el caso. La usurpación o arrogación ilegal de la ciudadanía romana habría tenido como consecuencia la condena capital65. Por tanto tenemos que concluir que no sabemos cómo, ni por qué, ni si Pablo fue trasladado a Roma. Si el encarcelamiento del apóstol en Jerusalén fue un hecho histórico, sólo se podría explicar su traslado a Roma mediante una apelación al Emperador basada en la posesión de la ciudadanía romana ${ }^{66}$. Pero dado que las tensiones internas e incoherencias de la presentación lucana y la problemática de la ciudadanía paulina han indicado que Pablo no era romano, y que no pudo apelar al Emperador, podemos por tanto concluir que Pablo no fue llevado prisionero a Roma.

¿Cómo podemos, entonces, explicar la mención de la ciudadanía romana para Pablo por parte de Lucas? Para esta pregunta no existe una respuesta segura, pero se han de tomar en consideración dos soluciones propuestas. A) Sería posible (pero en ningún caso seguro), que Pablo poseyera la ciudadanía de Tarso. Lucas habría ampliado entonces la ciudadanía de Tarso con la romana. Con ello pretendía el evangelista resaltar la figura del apóstol67. La obtención y posesión de la ciudadanía de Tarso plantea algunos interrogantes que no son fáciles de solucionar, como ya se ha indicado anteriormen425.

64. Para una amplia explicación de esta reconstrucción cfr. mi tesis Religionspolitik 273-

65. Claudio ordenó la ejecución de personas que habían usurpado la ciudadanía romana, Suetonio, Claud. 25,3.

66. G. Lüdemann, Christentum 250.

67. En contra se expresa J.C. Lentz, Portrait 24. 
te. B) Otra explicación para la presentación lucana se podría buscar en la intención misionera propagandista de la obra del evangelista en relación con el destinatario o los lectores. La afirmación de la ciudadanía romana de Pablo sería entonces una invención lucana. La dedicación de la obra a Teófilo muestra que el compositor de Hechos tenía relaciones personales con él y quería expresarle su amistad o agradecimiento (quizás fuera un mecenas o bienhechor de Lucas), así como el deseo de que Teófilo diera a conocer esta obra en su círculo de amigos. ¿Quién era este кpó $\tau \sigma \tau о \varsigma$ Teófilo68? Dejando a parte una noticia dudosa que aparece en las Pseudo-Clementinas, según la cual Teófilo vivía en Antioquía69, tenemos que decir que no sabemos nada de él. Los estudiosos modernos opinan, no obstante, que sería una personalidad histórica ${ }^{70}$. El concepto кpó $\tau$ $\sigma \tau 0 \zeta$ en Lc 1,3 no obliga necesariamente a suponer que Teófilo era un empleado oficial o un alto rango, pero es muy probable que fuera un ciudadano romano. Es cuestionable si ya era cristiano cuando Lucas escribió Hechos. Es de suponer que los cristianos y sobre todo esos con ciudadanía romana en Asia Menor estuvieran presionados por parte de la sociedad o incluso perseguidos cuando fueron escritos los Hechos por considerarlos como traidores de las costumbres romanas. En tal situación Lucas quiere mostrar a Teófilo con la presentación de Pablo como civis romanus, que incluso el gran apóstol tuvo que sufrir, a pesar de que también era un ciudadano romano, y que el cristianismo no estaba en contraposición con el ser romano, sino que era una religión apropiada para ciudadanos del imperio. Pablo se convierte en la obra de Lucas en modelo para los cristianos con ciudadanía romana de los años $80 \mathrm{~d}$. C., y éstos son invitados o bien a convertirse al cristianismo o bien a no abandonarlo, en caso de que ya lo fueran.

\section{3.- El traslado de Pablo a Roma}

Ante nosotros todavía tenemos la pregunta: ¿por qué y cómo Lucas construyó el relato de un traslado del apóstol a Roma, cuando Pablo no había

68. El adjetivo $\rho \alpha \dot{\tau} \tau 1 \sigma \tau 05$ aparece en el NT en pocas ocasiones: Lc 1,3; Hch 23,26; 24,3 y 26,25 (en el tratamiento de una autoridad oficial). El término aparece frecuentemente en dedicaciones de obras literarias, cuyo destinatario no tiene que tener necesariamente un puesto oficial. Su traducción en latín sería con la palabra egregius o optimus.

69. Ps-Clementinas, Recog X 71,2: ... ita ut omni avididatis desiderio Theofilus, qui erat cunctis potentibus in civitate sublimior, domus suae ingentem basilicam ecclesiae nomine consecraret.

70. F. Bovon, Luk 39. 
podido apelar al Emperador? Una solución segura no existe para este problema, pero intentaré ofrecer al menos una posible explicación para el relato de Lucas. Para ello examinaré fuentes judías que narren y testimonien traslados de presos desde Cesárea a Roma bajo la administración de los Procuradores Félix y Festo. Esta investigación puede aclarar los últimos capítulos de Hechos.

Algunos autores han intentado -aunque sin ser convincentes- fundamentar el traslado de Pablo a Roma como consecuencia de un proceso o procedimiento extra ordinem. Apoyándose en P. Garnsey ${ }^{71}$, W. Stegemann afirma que "Pablo, prisionero no romano, fue trasladado desde Jerusalén, mejor dicho, desde Cesárea a Roma para ser procesado, porque él era un personaje político y público relevante, lo que pudo inducir al Procurador a enviar este caso a una instancia superior, a Roma. Como consecuencia de la situación política en Palestina es casi seguro que el nuevo gobernador, quien acababa de tomar posesión de su cargo, no quisiera decidir en este caso sino entregarlo a Roma"72. Contra esta afirmación hay que subrayar y dejar bien claro que Pablo no constituía para Festo una personalidad importante y que en la provincia de Palestina no poseía ningún poder ni prestigio político, dado que el apóstol desde su conversión sólo había estado allí esporádica y temporalmente y desde el conflicto de Antioquía el apóstol no gozaba de simpatías entre los judeocristianos de Siria y Palestina, sino todo contrario. Para un gobernador, que decretó multitud de condenas a muerte, el asunto de Pablo no tuvo que constituir más que un asunto sin importancia con el que difícilmente habría molestado al tribunal imperial73. Además es improbable que un gobernador hubiera enviado a un romano por discusiones religiosas para que fuera juzgado por el Emperador, dado que eso hubiera mostrado claramente al Emperador que su subordinado era totalmente incompetente, pues no sabía solucionar un caso tan sencillo. Si Pablo hubiera sido considerado como un rebelde judío contra los romanos, el gobernador no habría dudado ni un momento en entregarlo a sus enemigos judíos, o él mismo lo habría mandado ajusticiar sin reparos, como los romanos habían hecho anteriormente con tan-

71. P. Garnsey, "Lex" 184, afirma que Festo no estaba obligado a ocuparse de la exigencia de Pablo. Él envió al apóstol a Roma, porque éste "era un hombre de cierta importancia por su status de ciudadano y a causa de su fama y notoriedad. Era un hombre difícil de controlar y a donde iba causaba problemas".

72. W. Stegemann, "Apostel" 212. Este autor presenta una analogía para esta interpretación: el caso el tejedor Jonatan en Josefo, BJ VII 449ss. Pero las diferencias entre los dos casos son obvias.

73. W. Schmithals, Apg 219. 
tos otros sin tener que enviarlos a Roma. La presentación lucana del viaje a Roma es además inimaginable para un preso político en aquel tiempo, pues no se trataba de ningún turista o peregrino con acompañamiento hacia Roma. En el relato de Lucas da la impresión que el centurión que custodiaba a Pablo fuera más bien su sirviente dado que accede a todos los deseos del apóstol.

W. Schmithals ${ }^{74}$ propone una explicación para los acontecimientos históricos que pudieran estar detrás de la composición lucana. Él concluye de la falta de indicios en las fuentes desde la llegada de Pablo a Jerusalén, que Pablo no fue apresado en Jerusalén, sino que viajó como hombre libre a Roma. Fue en la capital del imperio donde fue apresado y finalmente sufrió el martirio ${ }^{75}$.

Indicaciones de cómo Lucas ha construido el traslado del apóstol se pueden obtener mediante una comparación de los últimos capítulos de Hechos con las obras históricas de Josefo que relatan acontecimientos del tiempo de Félix y Festo. A pesar de que Lucas y Josefo tenían objetivos apologéticos casi contrarios en la presentación de estos Procuradores romanos, sin embargo concuerdan en algunos detalles ${ }^{76}$. Ambos escritores mencionan a Drusila como esposa de Félix ${ }^{77}$, y al egipcio con los sicarios como el provocador de una revuelta contra Roma en Judea ${ }^{78}$. Presentan al Procurador como una persona sin escrúpulos, porque soborna y se deja sobornar ${ }^{79}$. Los paralelismos entre Hch 21,38 y BJ II 261-263 son evidentes ${ }^{80}$. Según K.-S. Krieger ${ }^{81}$

74. M.-E. Boismard - A. Lamouille, Actes vol. 3,293-316, reconocen en la narración del traslado del apóstol a Roma dos relatos distintos: un informe de un viaje y Act I. Según el informe de viaje, Pablo consiguió llegar a Roma como hombre libre. Según Act I llegó como prisionero. Contra esta tesis véase J. Murphy-O'Connor, Paul 353s.

75. W. Schmithals, Apg 219.

76. Véase una visión de conjunto en S. Mason, Josephus 204-223.

77. Hch 24,24; Josefo, AJ XX 141-143, menciona como Félix propuso a Drusila que abandonara a su marido para que se casara con él.

78. Hch 21,37; Josefo, AJ XX 169-172; BJ II 161-163.

79. Hch 24,26: "Félix esperaba al mismo tiempo que Pablo le diera dinero". Josefo, AJ XX 165: Félix intenta sobornar a un sicario para que asesine al sumo sacerdote Jonathan.

80. Josephus, BJ II 261-263: "Pero mayor daño causó a todos los judíos un hombre egipcio, falso profeta... Juntó con él casi treinta mil hombres, engañándolos con vanidades y trayéndolos consigo de la soledad adonde estaban, al monte que se llama de las Olivas... Habíase juntado para poner por obra esta maldad mucha gente de guarda; pero viendo esto Félix, proveyó en ello; y saliéndoles con la gente romana muy armada y en orden ... dióle la batalla. Huyó salvo el egipcio con algunos; y presos los otros muchos fueron puestos en la cárcel, y los demás se volvieron a sus tierras".

81. K.-S. Krieger, Geschichtsschreibung 147. El género "Goetes" se caracteriza por la siguiente estructura: Un hombre nombrado nominalmente entra en escena; encuentra un grupo de seguidores que tienen que buscar refugio en el desierto. Los seguidores al final son ajusticiados. En Hch 21,38 se trata de un fragmento de este género, pues falta el final típico de dicha narración. Cfr. también el caso de Teudas (Hch 5,36; Josefo, AJ XX 97s). 
pertenecen los dos textos al genero literario de "narraciones Goetes", las cuales encontraron ya existentes tanto Josefo como Lucas. Independientemente uno de otro toman las mismas tradiciones, que conocieron en distinta disposición, las reelaboraron y las integraron en sus respectivas narraciones.

La emboscada contra Pablo (Hch 23,12-22; 25,3: "Pidieron que lo trasladara a Jerusalén, mientras preparaban una celada para matarle en el camino") pertenece también al modelo de "narraciones-Goetes". Josefo informa, por su parte, de una emboscada similar contra el sumo sacerdote Jonatán (AJ XX 163s). Las diferencias entre ambos relatos están en algunos detalles intencionales, ya que Josefo intenta difamar a Félix con la presentación de los hechos, mientras que Lucas por el contrario a los judíos y al Sanedrín.

En AJ XX 180s Josefo describe la existencia de luchas y tensiones entre los judíos. El término técnico $\sigma \tau \alpha ́ \sigma r \varsigma$ se emplea en este pasaje no sólo en el sentido de conflicto, sino también con el significado de "lucha entre partidos"

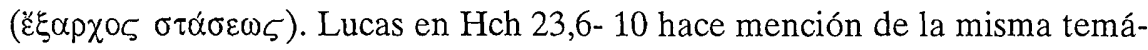
tica: la lucha entre los distintos partidos judíos (conflicto entre saduceos y fariseos), la cual se había convertido en $\sigma \tau \alpha \dot{\sigma} \sigma \varsigma$.

La última noticia del periodo de Félix que transmite Josefo es muy interesante para nosotros: se trata de los disturbios en Cesárea entre los judíos y los sirios ocasionados por las pretensiones de ambos bandos con el fin de que la ciudad fuera declarada judía o siria. Por tanto, el tema en discusión es también el de la ciudadanía. "Estando aún esta revuelta en pie, envió la gente más noble de ambas partes por embajadores a Nerón, para que en su presencia se disputase la causa y los privilegios y se averiguase lo que de derecho convenía". El conflicto giraba en torno a la hegemonía de estos grupos en Cesárea, sobre todo en cuanto a los derechos y privilegios. Un término técnico en nuestro texto es el concepto $\sigma \tau \alpha \dot{\alpha} \sigma \varsigma 5$ (revuelta, diferencias de opinión, facción, desacuerdo). Ese mismo concepto viene utilizado en la acusación que presenta Tértulo contra Pablo ante el Procurador: "Hemos encontrado esta peste de hombre que provoca altercados $(\sigma \tau \alpha \dot{\sigma} \sigma \varepsilon 1 \zeta)$ entre los judíos de toda la tierra y es el jefe principal de la secta de los nazoreos" (Hch 24,5).

Un texto paralelo a BJ II 266-270 lo encontramos también en AJ XX 173-178: "Se produjo una disensión entre los judíos que vivían en Cesárea y los sirios de la misma ciudad, acerca de la igualdad de los derechos de ciudadanía... El gobernador, después de capturar a los cabecillas de la revuelta, los mandó azotar". El motivo de la revuelta viene expresada con la expresión $\pi \varepsilon p^{\prime}$ i $\sigma \circ \pi \circ \lambda \imath \tau \varepsilon i \alpha_{\zeta}{ }^{82}$. El desenlace final del episodio es distinto del que tene-

82. Sobre los conflictos en Cesárea véase I.L. Levine, The Jewish-Greek Conflict in First 
mos en BJ. La embajada a Roma (BJ) no aparece en AJ y la pospone para cuando Porcio Festo fue enviado por Nerón para suceder a Félix. Los principales de los judíos que vivían en Cesárea se dirigieron a Roma para acusar a Félix. Dos de los sirios principales de Cesárea, mediante la donación de gran cantidad de dinero, persuadieron a Burro, instructor de Nerón y encargado por éste de los asuntos de las regiones griegas, que pidiera a Nerón que privara a los judíos del derecho de ciudadanía que les era común con los sirios. Burro se lo pidió al Emperador y lo obtuvo y envió un rescrito, que fue la causa de todos los males que posteriormente afligieron a nuestro pueblo (AJ XX 182) ${ }^{83}$. Vemos, por tanto, que en Cesárea en tiempo de este Procurador existían conflictos en torno a la ciudadanía y que para intentar solucionarlos enviaron una delegación al Emperador. Estos son los mismos temas que tenemos en Hechos y que vienen aplicados a Pablo.

Las coincidencias entre Josefo y Lucas han llevado a algunos investigadores a suponer que Lucas conoció las obras de Josefo, de las cuales se acordaba de forma imprecisa o cambió conscientemente algunos datos y detalles para que se adaptaran al objetivo de su obra84. Este tema no es el objeto de nuestro estudio y por tanto no lo discutiré aquí; pero presupongo que o Lucas dispuso de las mismas fuentes que usó Josefo, o bien había leído sus obras.

Hasta ahora hemos constatado algunas coincidencias de hechos narrados entre el historiador judío y Lucas. Si comparamos la narración de Josefo, Vita 13-16 con el traslado del apóstol a Roma, quedaremos todavía más sorprendidos por la semejanza. Josefo narra una embajada a Roma, que él encabezaba con el objetivo de liberar a unos sacerdotes judíos prisioneros. El texto dice así:

Century Caesarea, in: JJS 25 (1975) 381-397; A. Kasher, The Isopoliteia Question in Caesarea Maritima, in: JQR 68 (1977) 16-27.

83. Este párrafo contradice tanto temporal como en el contenido la presentación de BJ II 270 , según la cual Félix envió por su propia iniciativa delegaciones de las dos partes, de judíos y de sirios, a Roma para clarificar ante el Emperador sus pleitos. BJ narra sólo el envío de

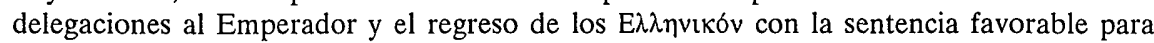
éstos. BJ no dice nada del proceso en Roma.

84. S. Mason, Josephus 213f.224, aboga por una dependencia de Lucas de las obras de Josefo: "Él no concuerda con Josefo en detalles... Sus eventos políticos en Judea son comprensibles si había leído algunas partes de Josefo" (pg. 213). "Los desacuerdos se pueden explicar como conflación de los datos de Josefo, resultado de una memoria imperfecta o una esquematización deliberada" (pg. 224). G.E. Sterling, History and Self- Definition. Josephus, Luke-Acts and Apologetic Historiography (NT.S 64), Leiden 1992, no ve, por el contrario, ninguna dependencia de Lucas del escritor judío. 
"Después de haber cumplido los veintiséis años, acaeció que fui a Roma por la razón que voy a referir: en la época en que Félix era Procurador de Judea, por un motivo nimio y fortuito ( $\mu$ ıрò̀ $v \kappa \alpha 1$

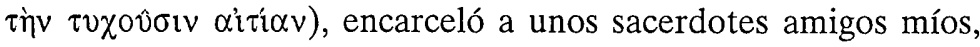
hombres honorables, y los envió a Roma para que dieran explicaciones al César. Yo deseaba encontrar el modo de salvarlos, sobre todo sabiendo que, ni siquiera en la desgracia, en ningún momento habían olvidado su piedad hacia Dios y se alimentaban de higos y nueces, y llegué a Roma después de una travesía plagada de peligros. Resulta que nuestra nave naufragó en medio del Adriático; éramos unos seiscientos y nadamos toda la noche. Al amanecer, gracias a la providencia divina, apareció ante nosotros una nave de Cirene. A mí y a algunos más, en total unos ochenta, que nos adelantamos del resto, nos subieron a bordo. Ya a salvo en Dicearquía, a la que los italos llaman Puteoli, entablé amistad con Alituro, un actor de familia judía muy estimado por Nerón. Por medio de él fui presentado a Popea85, la mujer del César, y sin demora me ocupé de solicitarle la liberación de los sacerdotes. Cuando hube obtenido de Popea, además de ese favor, considerables obsequios, regresé a mi patria" 86 .

El relato lucano del viaje de Pablo a Roma muestra algunas características que son importantes en relación con el relato del historiador judío: tanto Josefo como Pablo llegan a Roma después de una tormenta y un naufragio, lo cual nos hace recordar el relato de Jonás y los tópicos tradicionales sobre viajes marinos llenos de peligros ${ }^{87}$. Cuando las delegaciones llegan a Puteoli, Josefo entra en contacto inmediatamente con los judíos, Pablo en un primer

85. En otro texto (AJ XX 195) Josefo describe a la emperatriz como $\theta \varepsilon o \sigma \varepsilon \beta \dot{\eta} 5$, temerosa de Dios. Es discutido si este término hay que entenderlo aquí en un sentido técnico judío. Apoyándose en E.M. Smallwood, H. Lichtenberger, "Josephus" 253, interpreta esta expresión aplicada a Popea de la siguiente forma: "La mejor manera de entender este término aplicado a ella, es caracterizándola como 'religiosa', es decir, ella tenía simpatías hacia las convicciones religiosas de los judíos". Véase también $H$. Lichtenberger, Jews and Christians in Rome in the Time of Nero: Josephus and Paul in Rome, in: ANRW II 26.3 (1996) 2146ss.

86. Traducción de $M$. Rodríguez de Sepúlveda, Flavio Josefo. Autobiografía contra Apión (Biblioteca clásica Gredos 189), Madrid 1994, 102.

87. E. Lohse, Paulus 263, considera que el narrador de Hechos se sirvió de motivos concretos que eran muy apreciados en relatos de viajes, pero descarta que el narrador fuera testigo ocular. 
momento con los cristianos (quienes todavía formaban una secta judía) y después con los judíos ${ }^{88}$. La semejanza entre los dos viajes a Roma es tan asombrosa que $B$. Orchard ha propuesto la identificación de los sacerdotes judíos con Pablo y su acompañante (Aristarco): Pablo y su acompañante son los únicos candidatos, cuya historia conocida coincide con los detalles del relato de Josefo. Aunque no se puede aceptar la conclusión a la que llega este autor, sin embargo hay que subrayar el paralelismo entre los dos textos.

En el relato de Josefo, algunos sacerdotes fueron enviados encadenados

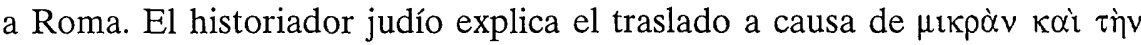
$\tau$ $\chi 0$ vorv $\alpha i \tau i \alpha v$. Esta indicación puede llevar a suponer que no sólo los ciudadanos romanos que apelaban al Emperador eran juzgados en Roma, sino

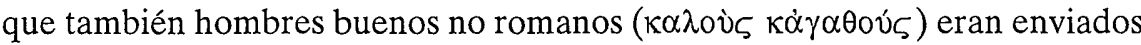
como prisioneros al Emperador. Esto concuerda muy bien con la presentación que nos hace Lucas, según la cual Pablo fue enviado a Roma, a pesar de que él era inocente. Podría dar la impresión de que no sólo Pablo, sino otros importunaban al César con asuntos sin importancia. A la presentación que hace Josefo, tenemos que objetar que el escritor judío no indica ni menciona las verdaderas razones del traslado de los sacerdotes por motivos apologéticos. A Roma no eran enviadas personas de las provincias para que fueran juzgadas por el Emperador de acusaciones sin importancia. El Emperador no perdía el tiempo con eso. Por tanto, la acusación contra los sacerdotes tenía que ser política, es decir, que se tratara de cuestiones de la política de seguridad en Palestina. Con acierto afirma S.J.D. Cohen ${ }^{89}$ que detrás de la frase $\delta 1 \alpha$

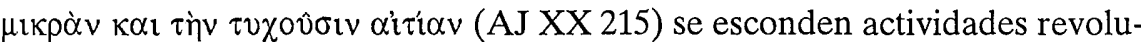
cionarias. Si tenemos presente la situación política en Palestina pocos años antes del estallido de la guerra judía, entonces podemos suponer que el traslado de los sacerdotes revolucionarios e instigadores no es un caso banal90. El Procurador quería mostrar al Emperador con el traslado de esas personas

88. B. Orchard, "Josephus" 248. Así explica este autor el papel jugado por Josefo en la liberación del apóstol: Las noticias sobre Popea pudieron llevar a la familia de Pablo y a la iglesia de Jerusalén a idear un plan para liberar a Pablo y a su acompañante mediante la ayuda de la emperatriz. Si los amigos de Pablo hubieran buscado a un emisario y elegido al joven Josefo, su elección no hubiera levantado ninguna sospecha. Josefo hubiera sido la mejor elección dado que era hábil y ambicioso (pg. 259).

89. S.J.D. Cohen, Josephus 61s: "V. 13 muestra que esta era una frase que Josefo usaría para encubrir actividades revolucionarias. Los sacerdotes no eran enviados a Roma para hacer allí su defensa ante el Emperador por motivos insignificantes, ni, si es que fueron enviados, habría ido un joven a ayudarlos, quien pronto estaría dirigiendo las fuerzas revolucionarias en Galilea. Josefo quiere subrayar que él era pro-romano y por tanto afirma que los sacerdotes no eran revolucionarios".

90. Me parece errónea la afirmación de T. Rajak, Josephus 39: "Que Josefo no mencio- 
que la situación en Palestina había empeorado notablemente. Incluso los sacerdotes, que hasta entonces habían tolerado más o menos a las fuerzas ocupantes, estaban ahora de parte de los rebeldes, con lo cual el Procurador quería justificar sus duros procedimientos contra los rebeldes y su política represiva.

Por tanto, Lucas usa para el traslado de Pablo a Roma viejas narraciones o motivos tópicos junto con informaciones históricas que estaban en relación con algunas personalidades (como eran estos Procuradores) y las cuales se adecuaban al objetivo apologético y misional de su narración. Es casi seguro que Lucas conocía tanto los altercados entre judíos y sirios en Cesárea referentes a la ciudadanía, sus embajadas a Roma y algunos detalles sobre los Procuradores, así como el traslado a Roma de algunos sacerdotes judíos rebeldes. Esta última tradición ofreció al escritor cristiano el marco para su presentación del traslado de Pablo a Roma. Hay que dejar bien claro que Lucas aquí no sólo se hace eco de elementos tradicionales, sino que además los reelabora y ordena su información en ese marco narrativo. También tenía a su disposición tradiciones sobre un viaje del apóstol a Roma, de su actividad misionera en dicha ciudad, así como de su encarcelamiento en la capital del imperio ${ }^{91}$. Estas dos últimas tradiciones fueron usadas en la narración lucana para permitir a Pablo una actividad misionera sin trabas en Roma.

Seguramente el apóstol tuvo dificultades con las autoridades romanas en la capital, fue hecho prisionero y condenado. Ante esos hechos históricos, Lucas estaba ante el dilema, cómo tenía que contar a Teófilo, probablemente un ciudadano romano interesado en el cristianismo, el encarcelamiento de Pablo sin culpar directamente a los romanos. Quería dejar bien claro que Roma no había condenado el cristianismo, y que la creencia en Jesús como religión también era aceptable y digna para los romanos, pues no infringía ninguna ley, y eso incluso había sido reconocido por algunas autoridades romanas, como habían sido los Procuradores de Cesárea. Lucas trasladó por motivos apologéticos el encarcelamiento del apóstol de Roma a Jerusalén,

ne su propia embajada fuera de su vida es curioso y sólo podemos concluir que el incidente era uno de rutina". También $P$. Bilde, Josephus 31, considera el envío de sacerdotes ante el Emperador como una "costumbre (y que ocurría frecuentemente en Palestina)". La ejecución de revolucionarios y rebeldes en Palestina era una rutina, pero el traslado frecuente de presos a Roma para que fueran allí juzgados perjudicaba la imagen del Procurador ante el Emperador y ante la justicia imperial. Por tanto sólo los casos especiales eran enviados a Roma.

91. Sobre un doble encarcelamiento del apóstol en Roma, apoyado por un pasaje de Eusebio, HE II 22,1-7, así como su martirio véase mi trabajo Religionspolitik 420-425. 
con el fin de que los judíos aparecieran como los culpables del destino el apóstol, y los romanos por el contrario como inocentes. Al mismo tiempo el narrador hace aparecer a los dos Procuradores y al mismo rey Agripa como testigos de que Pablo era inocente y leal al imperio. La religión de Pablo, según Lucas, había sido reconocida y aceptada incluso en la misma Roma: el hecho mismo de que los soldados que lo custodiaban en Roma no prohibieran ni impidieran la proclamación del evangelio se puede interpretar como una aceptación tácita. En el relato de Lucas el apóstol consigue ser testigo de Jesús ante el mismo Emperador. El evangelista debía ser consciente de que sólo la gente importante ${ }^{92}$ y los ciudadanos romanos podían ser enviados por el Procurador a Roma ante el Emperador.

Según W. Schmithals ${ }^{93}$ la política apologética de Lucas es la única razón para la presentación lucana del traslado de Pablo a Roma. Este aparece presentado como quien viene enviado a Roma a causa de la instigación judía para poder testimoniar y probar la lealtad política de los cristianos en Roma y delante del mismo Emperador. La lealtad de los cristianos en tiempo de Lucas es comparable por tanto a esa del apóstol, quien apeló al César, porque había sido acusado por venganza, aunque era inocente. Es presumible que los cristianos tuvieran en tiempo de Hechos algunos problemas referentes a la lealtad al imperio y se les considerara como desleales. Lucas presenta en esta narración apologética el camino de sufrimiento de Pablo en paralelismo a la pasión de Jesús, la cual también había acontecido por acusaciones judías, mientras que Pilatos y Herodes habían puesto en evidencia la inocencia de Jesús. La pasión y muerte de Jesús se convierten en un martirio ejemplar. Lucas consigue con su relato del traslado de Pablo una teología de la cruz paulina.

Las informaciones sobre la estancia del apóstol en Roma y sobre el fin de su vida son tan vagas y contradictorias que poca cosas podemos afirmar con seguridad. La mayoría de estudiosos acepta que murió martirizado. La información más antigua no canónica la tenemos en 1 Clem 5,5-7; 6,1, quien afirma que fue martirizado (cfr. 2 Tim 4,6-8) como Pedro. El texto no afirma explícitamente que muriera en Roma. Según la tradición Pablo fue ejecutado con la espada. La primera referencia explícita que menciona la muerte del

92. Josefo nos narra cómo también Eleazar, el principe de los ladrones, fue capturado y enviado a Roma en tiempos de Félix (AJ XX 161; BJ II 253). El Procurador pretendía mostrar al Emperador con ello que su política contra los ladrones (sicarios...) era eficaz. Se debe dejar bien claro que Pablo en Palestina no constituía para los romanos ningun peligro, ni era una personalidad o ladrón buscado.

93. W. Schmithals, Apg 219f. 
apóstol por decapitación aparece en el Martyrium Pauli, el segmento final de Acta Pauli (ca. 160 d. C.) y en Tertuliano, De Praescriptionae Haeriticorum 36,1-3 (ca. 200). Esta indicación del tipo de muerte viene deducido probablemente de su presunta ciudadanía romana mencionada en Hechos y porque se pensó, como después pensaron también escritores cristianos tardíos ${ }^{94}$, que la decapitación era un modo más benévolo y honorable de ejecución.

Mi explicación para el traslado de Pablo a Roma es sólo hipotética y no quiere ser más que eso. Dada la falta de información de las fuentes no se puede obtener una reconstrucción fiable de los últimos años del apóstol. Pero la narración lucana no se puede considerar como histórica.

\author{
David Álvarez Cineira \\ Estudio Teológico Agustiniano \\ Valladolid
}

94. Los testimonios antiguos sobre el martirio del apóstol tanto en literatura apócrifa cristiana como en la patrística los recoge en su libro H.W. Tajra, Martyrdom. 


\section{Bibliografía}

BILDE, P., Flavius Josephus between Jerusalem and Rome: his life, his works and their importance (JSPE.S 2), Sheffield 1988.

Bleicken, J., Senatsgericht und Kaisergericht. Eine Studie zur Entwicklung des Prozeßrechtes im frühen Prinzipat (AAWG.PH 53), Göttingen 1962.

Boismard, M.-É. - Lamoulle, A., Les Actes des deux Apôtres. Vol. 3: Analysis littéraires (EtB.NS 14), Paris 1990.

Bovon, F., Das Evangelium nach Lukas. 1. Teil: Lk 1,1-9,50 (EKK III 1), Zürich Neukirchen-Vluyn 1989.

CArrez, M., Note sur les évènements d'Éphèse et l'appel de Paul à sa citoyenneté romaine, in: REFoulé, F. (Hrsg.), À cause de l'Évangile. FS. für J. Dupont (LD 123), Paris 1985, 769-777.

Collange, J.-F., L'Épître de saint Paul aux Philippians (CNT Xa), Neuchâtel 1973.

Deissmann, A., Licht vom Osten. Das neue Testament und die neuentdeckten Texte der hellenistisch- römischen Welt, 4. Aufl., Tübingen 1923.

Doer, B., Civis Romanus sum. Der Apostel Paulus als römischer Bürger, in: Helikon 8 (1969) 49-69.

FERENCZY, E., Rechthistorische Bemerkungen zur Ausdehnung des römischen Bürgerrechts und zum ius Italicum unter dem Prinzipat, in: ANRW II 14 (1982) 1017-1058.

GARNSEY, P., The Lex Iulia and Appeal under the Empire, in: JRS 56 (1966) 167-189.

GNilKA, J., Paulus von Tarsus. Zeuge und Apostel (HThK.S 6), Freiburg i. Br. - Basel Wien 1996.

HaACHer, K., Zum Werdegang des Apostels Paulus. Biographische Daten und ihre theologische Relevanz, in: ANRW II 26.2 (1995) 815-938.

Haenchen, E., Die Apostelgeschichte (KEK 3), 6. Aufl., Göttingen 1968.

Hengel, M., Der vorchistliche Paulus, in: Hengel, M. - Heckel, U., Paulus und das antike Judentum (WUNT 58), Tübingen 1991, 188-193.

Holtheide, B., Römische Bürgerrechtspolitik und römische Neubürger in der Provinz Asia (HochschulSammlung Philosophie, Geschichte Bd. 5), Freiburg i. Br. 1983.

KennSCHerPer, G., Der Apostel Paulus als römischer Bürger, in: StEv 2 (1964) 411-440.

KRIEGER, K.-S., Geschichtsschreibung als Apologetik bei Flavius Josephus (TANZ 9), Tübingen - Basel 1994.

LENTZ, J.C., Luke's Portrait of Paul (MSSNTS 77), Cambridge 1993.

Lichtenberger, H., Josephus und Paulus in Rom. Juden und Christen in Rom zur Zeit Neros, in: Koch, D.A. - Lichtenberger, H. (Hrsg.), Begegnung zwischen Christentum und Judentum in Antike und Mittelalter, FS. für H. Schreckenberg (SIJD 1), Göttingen 1993, 245-261.

Lintort, A.W., Provocatio. From the struggle of the Orders to the Principate, in: ANRW I 2 (1972) 226-267.

Llewelyn, S.R., Claudius Lysias (Acts 22) and the Question of Paul's Roman Citizenship, in: Horsley, G.H.R. (ed.), New Documents Illustrating Early Christianity, Bd. 4, Macquarie Universtiy 1992, 152-155.

LoHSE, E., Paulus. Eine Biographie, München 1996.

Lüdemann, G., Das frühe Christentum nach den Traditionen der Apostelgeschichte. Ein Kommentar, Göttingen 1987.

Mason, S., Josephus and the New Testament, Peabody, Mass. 1992 
Mélèze-Modrezejewksi, J., Les tourments de Paul de Tarse, in: Ninci, G. - Thur, G. (eds.), Symposium 1988. Vorträge zur griechischen und hellenistischen Rechtsgeschichte (Siena - Pisa, 6.-8. Juni 1988), Köln - Wien 1990, 324-336.

Meyer E., Ursprung und Anfänge des Christentums. Bd. 3: Die Apostelgeschichte und die Anfänge des Christentums, 4.5. Aufl., Stuttgart - Berlin 1924.

Minnen, P. Van, Paul, the Roman Citizen, in: JSNT 56 (1994) 43-52.

Murphy-O'Connor, J., Paul. A Critical Life, Oxford 1996.

OrCHARD, B., Josephus and the unnamed Priests of his roman Mission, in: DR 113 (1995) 248-270.

RAJAK, T., Josephus. The Historian and his Society, London - Philadelphia 1983.

RAPSKE, B., The Book of Acts in Its First Century Setting. Bd. 3: The Book of Acts and Paul in Roman Custody, Grand Rapids, Mich. - Carlisle 1994.

Riesner, R., Die Frühzeit des Apostels Paulus. Studien zur Chronologie, Missionstrategie und Theologie (Wunt 71), Tübingen 1994.

Schmithals, W., Die Apostelgeschichte des Lukas (ZBK.NT III 2), Zürich 1982

Sherwin-White, A.N., Roman Society and Roman Law in the New Testament. The Sarum Lectures 1960- 1961, Oxford 1963.

- The Roman Citizenship, 2. Aufl., Oxford 1973.

SMallwood, E.M. The Jews under Roman Rule from Pompey to Diocletian: A Study in Political Relations (SJLA 20), 2. Aufl., Leiden 1981.

Stegemann, W., Zwei sozialgeschichtliche Anfragen an unser Paulusbild, in: EvErz 37 (1985) 480-490.

—War der Apostel Paulus ein römischer Bürger?, in: ZNW 78 (1987) 200-229.

SuHL, A., Paulus und seine Briefe. Ein Beitrag zur paulinischen Chronologie (StNT 11), Gütersloh 1975.

TAJRA H.W., The Trial of Paul (Wunt II 35), Tübingen 1989.

- The Martyrdom of St. Paul. Historical and Judicial Context, Traditions and Legendes (WUNT II 67), Tübingen 1994.

UnNik, W.C. VAN, Tarsus or Jerusalem. The City of Paul's Youth, in: Ibidem, Sparsa Collecta. Bd. 1: Evangelia, Paulina, Acta (NT.S 29), Leiden 1973, 259-320.

Wengst, K., Pax Romana. Anspruch und Wirklichkeit. Erfahrungen und Wahrnehmungen des Friedens bei Jesus und im Urchristentum, München 1986. 